\title{
SÍNDROME DE NECROSIS RETINIANA AGUDA TRAS PRIMOINFECCIÓN POR VARICELA
}

\section{ACUTE RETINAL NECROSIS SYNDROME FOLLOWING CHICKENPOX}

\author{
BOLÍVAR G ${ }^{1}$, GORROÑO MB ${ }^{2}$, PAZ J ${ }^{1}$, PAREJA J ${ }^{1}$
}

\section{RESUMEN}

Caso clínico: Varón de 34 años que desarrolló una necrosis retiniana aguda en su ojo izquierdo tres semanas después de padecer varicela. Con tratamiento sistémico precoz con aciclovir intravenoso (10 mg/kg/8 horas) y corticoides sistémicos ( $1 \mathrm{mg} / \mathrm{kg} / \mathrm{d}$ áa) la retinitis fue controlada y el paciente no sufrió pérdida de agudeza visual.

Discusión: La necrosis retiniana aguda es una complicación inusual de la varicela que necesita atención. Se ha descrito una forma leve durante el curso de la primoinfección por varicela zoster. Se recomienda un tratamiento adecuado y precoz durante la fase aguda de la enfermedad con aciclovir intravenoso para conseguir una buena agudeza visual y prevenir complicaciones.

Palabras clave: Necrosis retiniana aguda, varicela, tratamiento.

\section{ABSTRACT}

Case report: A 34-year-old male patient developed acute retinal necrosis in his left eye about three weeks after the onset of chickenpox. Systemic antiviral treatment with intravenous acyclovir (10 mg/kg/8hours) and systemic corticosteroids ( $1 \mathrm{mg} / \mathrm{kg} /$ day) controlled the retinitis and the patient suffered no loss of visual acuity.

Discussion: Acute retinal necrosis is an unusual complication of chickenpox. A mild form of this entity has been described during the course of primary varicella-zoster infection. Adequate and early therapy during the acute phase of the disease with intravenous acyclovir and systemic corticosteroids is recommended to achieve a satisfactory visual acuity and prevent complications (Arch Soc Esp Oftalmol 2007; 82: 579-582).

Key words: Acute retinal necrosis, chickenpox, treatment.

\section{INTRODUCCIÓN}

El síndrome de necrosis retiniana aguda (NRA) es una entidad poco frecuente que se caracteriza por retinitis vaso-oclusiva necrotizante, arteritis retiniana, vitritis y a menudo con posterior desarrollo de desprendi- miento de retina regmatógeno. Suele producirse por reactivación de virus del grupo herpes y afecta a pacientes sanos e inmunocomprometidos. Rara vez puede desarrollarse durante el curso de una primoinfección por el virus varicela-zóster, presentando estos casos un curso más leve y un pronóstico visual favorable (1-3).

\footnotetext{
Recibido: 31/5/06. Aceptado: 25/7/07.

Hospital Universitario Príncipe de Asturias. Alcalá de Henares. Madrid. España.

1 Licenciado en Medicina.

2 Doctor en Medicina.

Correspondencia:

Gema Bolívar de Miguel

C/. Miguel de Moncada, 15, $4 .^{\circ}$ A

28804 Alcalá de Henares (Madrid)

España

E-mail: gemabolivardemiguel@yahoo.es
} 


\section{CASO CLÍNICO}

Paciente varón de 34 años de edad diagnosticado de varicela tres semanas antes ya resuelta sin complicaciones. Acude a urgencias por presentar disminución de agudeza visual en su ojo izquierdo.

En la exploración oftalmológica presenta una agudeza visual corregida de 1 en el ojo derecho (OD) y de 0,6 en el ojo izquierdo (OI). El estudio con lámpara de hendidura demuestra en el $\mathrm{OI}$ un tyndall celular de $4+$, precipitados queráticos inferiores $(3+)$ y sin presentar la cornea tinción con fluoresceína, siendo normal el OD. La presión intraocular fue de $16 \mathrm{mmHg}$ en ambos ojos.

En la exploración fundoscópica inicial del OI se aprecia leve vitritis (1+) sin focos de retinitis.

Se instaura tratamiento tópico con corticoides y midriáticos. A los 2 días se observa leve disminución del tyndall celular (3+) en cámara anterior pero en fondo de ojo aparece un foco periférico de retinitis necrotizante en el área temporal asociado a vasculitis retiniana.

Se ingresa al paciente y se instaura tratamiento con aciclovir intravenoso (10 mgr $/ \mathrm{kg} / 8$ horas), antiagregación (ácido acetilsalicílico $150 \mathrm{mgr} / 24$ horas) y se mantiene el tratamiento tópico. Asimismo se realiza fotocoagulación profiláctica con láser de argón rodeando la zona de necrosis retiniana (figs. 1 y 2).

A las 48 horas y previa comprobación de una buena respuesta con disminución del foco de retinitis, se introducen corticoides sistémicos a dosis de $1 \mathrm{mg} / \mathrm{kg} / \mathrm{d}$, presentando una rápida mejoría de la

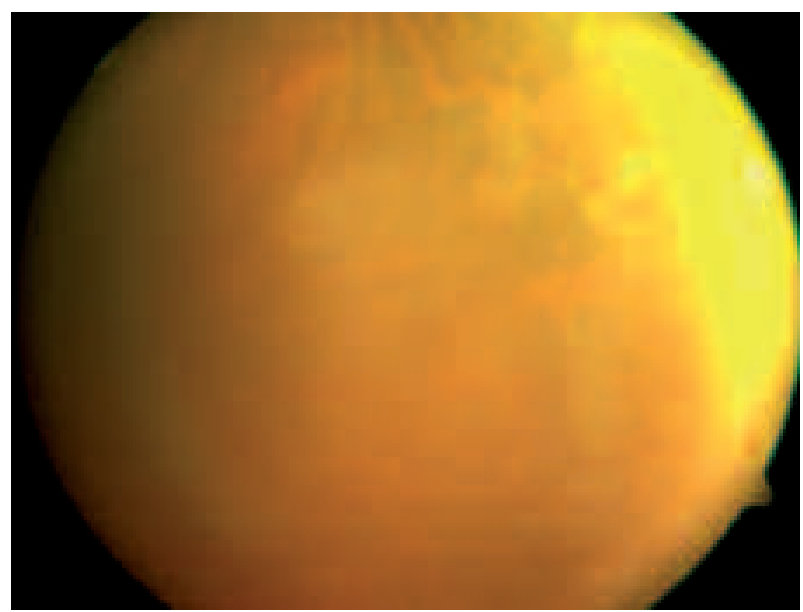

Fig. 1: Foto de la región temporal donde se aprecia la vitritis, zona tratada con láser y zona de retinitis.

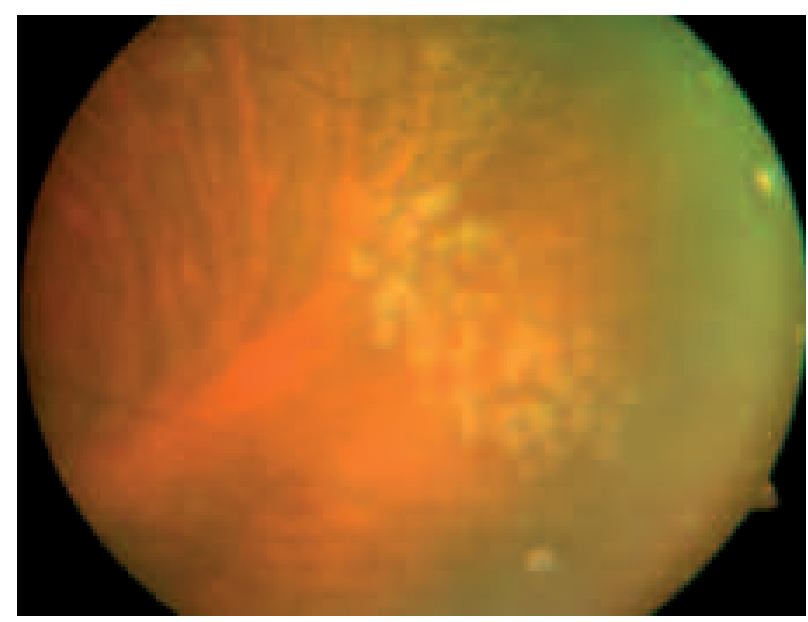

Fig. 2: Foto de la misma zona tras el tratamiento donde se observan las cicatrices de laser.

agudeza visual, con disminución de la vitritis y menor tamaño del foco de retinitis. A las 2 semanas se pasa a vía oral el tratamiento antiviral (famciclovir $500 \mathrm{mgr} / 12$ horas) y se inicia un descenso de corticoides de manera gradual a razón de $10 \mathrm{mgr}$ cada semana. Se continúa con el tratamiento antiviral a dosis de mantenimiento durante 6 semanas, realizando controles analíticos periódicos hemograma y bioquímica para detectar afectación renal.

Tras 6 meses del comienzo del cuadro, el paciente continúa asintomático, con una agudeza visual de unidad en OI, cicatrización de las lesiones retinianas y ausencia completa de actividad inflamatoria ocular en ambos ojos.

Durante el ingreso se constató la infección reciente por el virus varicela zoster mediante seroconversión.

\section{DISCUSIÓN}

La necrosis retiniana aguda como entidad clínica definida fue descrita por primera vez en 1971 por Urayama y col. Se caracteriza por una retinitis vaso-oclusiva necrotizante, con importante reacción inflamatoria en vítreo y cámara anterior, vasculitis retiniana $\mathrm{y}$, a menudo, desprendimiento de retina regmatógeno (hasta en un $75 \%$ ), con una rápida progresión en ausencia de tratamiento. Puede afectar tanto a pacientes sanos como a inmunocomprometidos. Aproximadamente $1 / 3$ de los pacientes desarrolla afectación bilateral, generalmente dentro de las 6 semanas y 4 meses de aparición de los sín- 
tomas en el primer ojo. Está causada por la reactivación de virus del grupo herpes, principalmente varicela zóster, herpes simple tipos 1 y 2 y, rara vez, citomegalovirus El tratamiento consiste en la administración sistémica de antivirales, corticoides y antiagregantes $(4,5)$.

Existe una forma más leve y menos frecuente de necrosis retiniana aguda asociada a la primoinfección por el virus varicela zóster, que se da en pacientes normalmente adultos, tanto sanos como inmunocomprometidos (1-3). Se ha descrito algún caso en niños (2). Los síntomas aparecen días después del diagnóstico de varicela, generalmente cuando la enfermedad ya ha remitido. El cuadro se presenta como una retinitis periférica que progresa lentamente, con moderada reacción inflamatoria en vítreo y cámara anterior, buena agudeza visual y sin desarrollo de desprendimiento de retina. La afectación bilateral es rara (sólo se ha descrito en paciente inmunocomprometido) (3).

Algunos autores postulan un papel incierto del tratamiento con aciclovir y corticoides debido al curso más leve y, probablemente limitado, de la enfermedad sin tratamiento (1), aunque se ha demostrado algún caso de mala evolución sin éste (3), por lo que parece recomendable su instauración.

El caso clínico que se describe representa un cuadro típico de necrosis retiniana aguda tras primoinfección por varicela, que presentó una evolución favorable no sólo por tratarse probablemente de una forma más leve de infección herpética sino también por la instauración precoz de un tratamiento sistémico adecuado.

Se ha postulado que este curso más indolente pueda ser debido a la buena respuesta celular y humoral que presenta el paciente frente a la varicela en el momento en que se desarrolla la retinitis (1), esto es, cuando la enfermedad cutánea ha remitido.

Debido a que las complicaciones oculares de la varicela son raras es importante tener presente esta entidad clínica como una posible complicación de la enfermedad, ya que un diagnóstico y tratamiento precoces son claves para el manejo óptimo de estos pacientes.

\section{BIBLIOGRAFÍA}

1. Culbertson WW, Brod RD, Flynn HW Jr, Taylor BC, Brod BA, Lightman DA, et al. Chickenpox-associated acute retinal necrosis syndrome. Ophthalmology 1991; 98: 16411646.

2. Matsuo T, Koyama M, Matsuo N. Acute retinal necrosis as a novel complication of chickenpox in adults. Br J Ophthalmol 1990; 74: 443-444.

3. Smith JR, Chee SP. Acute retinal necrosis syndrome complicating chickenpox. Singapore Med J 2000;41: 602-603.

4. Aizman A. Treatment of acute retinal necrosis syndrome. Drugs of Today (Barc) 2006; 42: 545-551.

5. Lau CH, Missotten T, Salzmann J, Lightman SL. Acute retinal necrosis, features, management, and outcomes. Ophthalmology 2007; 114: 756-762. 